\title{
An Absolute Determination of Viscosity Using a Torsional Pendulum
}

\author{
Hobart S. White* and Elliot A. Kearsley \\ Institute for Basic Standards, National Bureau of Standards, Washington, D.C. 20234
}

(July 28, 1971)

\begin{abstract}
An absolute measurement of the viscosity of di(2-ethylhexyl) sebacate with a torsional pendulum viscometer. The apparatus and calibration procedures are discussed and a detailed study of errors is made. The systematic error was estimated to be less than \pm 0.07 percent and the variability was shown to be less than \pm 0.07 percent. There is an unexplained difference of 0.3 to 0.4 percent between these measurements and measurements with a capillary instrument.
\end{abstract}

Key words: Absolute measurement; calibration; standard; torsional pendulum; viscosity.

\section{Introduction}

In calculating the accuracy of any physical measurement, it is not possible to be sure that all systematic errors have been taken into account. Moreover, the more the precision is improved, the greater is the possibility that an overlooked error is significant. A comparison of measurements made by different methods, each of which insofar as possible gives rise to quite different errors, is the most direct evidence of the completeness of the error estimates. For this reason, some years ago we attempted a measurement of viscosity by an absolute method and with errors not exceeding 0.1 percent in order to compare with measurements of presumed equal accuracy made with a capillary viscometer.

We chose to make the measurement with a viscometer consisting of a spherical shell suspended from a torsion wire and filled with the fluid whose viscosity is to be measured. The sphere is excited in torsional oscillation and the subsequent motion observed. In principle the viscosity of a Newtonian fluid may be obtained from either the period or the damping of this motion. In $1959[1]^{1}$ an analysis of the absolute torsional pendulum viscometer was published giving design criteria for the sphere and wire suspension which made the period sensitive to viscosity. That paper pointed out that modern techniques of measuring time intervals with great accuracy make this a promising method of measuring viscosity.

This paper describes the apparatus and the procedures used in calibrations and measurements. Difficulties encountered in obtaining a high degree of accuracy are discussed. The most reliable measurements reported are those obtained for Octoil S, a fluid with nominal kinematic viscosity of 19 centi-

\footnotetext{
${ }^{*}$ Retired from the Institute for Basic Standards, National Bureau of Standards, Wash ington, D.C. 20234.

' Figures in brackets indicate the literature references at the end of this paper.
}

stokes (cSt). These measurements were subsequently compared with an absolute measurement with a capillary instrument [2]. Measurements of a few other fluids were also reported with error estimates, primarily as a consistency check. A few measurements by the method of decrement are reported, but without complete error estimates.

\section{Apparatus and Method of Measurement}

The apparatus was designed to exhibit relatively high dependence of period on viscosity for a range from 10 to $150 \mathrm{cSt}$. Above and below this range, the dependence is markedly weaker. Figure 1 is a photograph of the complete apparatus showing the hollow sphere hanging above the thermostatted and vacuum tight housing within which it normally operates and the optical devices and timer used in measuring the period. Figure 2 is a schematic cross section of the thermostatted housing showing the sphere hanging on the torsion wire in the normal operating position. In operation, the sphere is excited in torsional oscillation, and the period is measured. The kinematic viscosity is then given by:

$$
\begin{gathered}
\nu=R^{2} \sqrt{\frac{K}{I_{0}}} \hat{\eta}(\tau, \alpha) \\
\tau=\sqrt{\frac{K}{I_{0}}}\left(\frac{T}{2 \pi}\right), \alpha=\frac{I}{I_{0}}
\end{gathered}
$$

where $\nu$ is the kinematic viscosity, $K$ is the torsion constant of the suspension, $R$ is the internal radius of the hollow sphere, $T$ is the period of the oscillation, $I$ is the moment of inertia of the empty sphere, and $I_{0}$ is the moment of inertia of the test fluid considered as a 


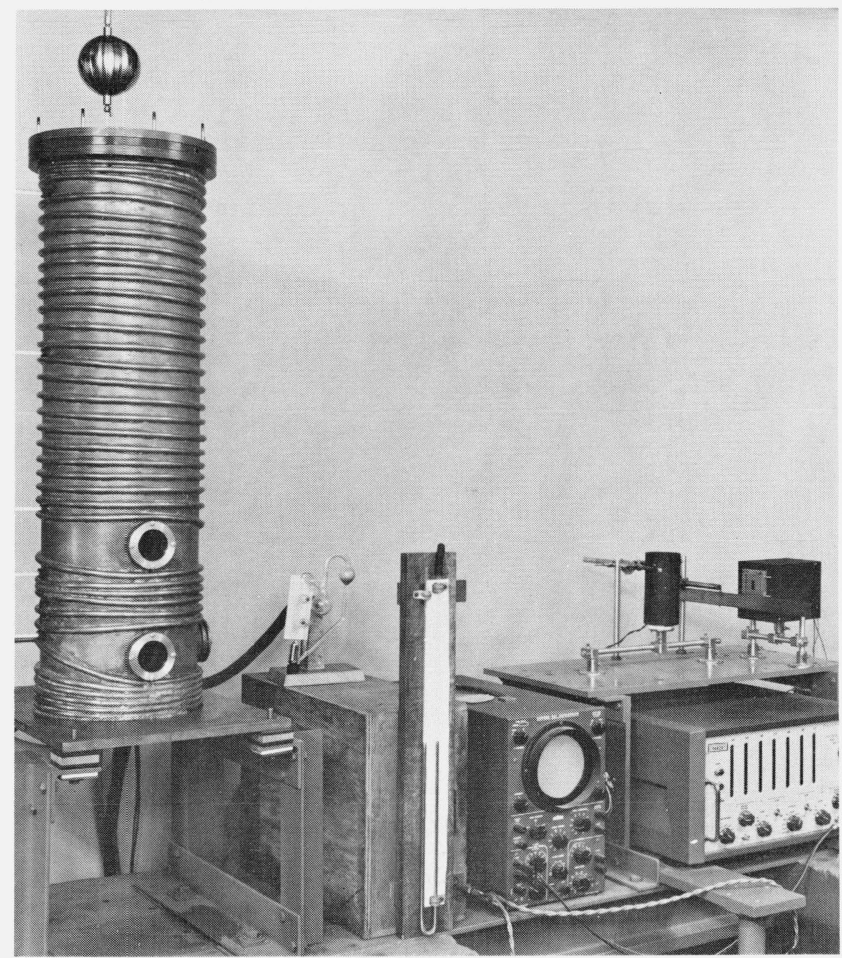

Figure 1. Photograph of the torsional pendulum viscometer. The sphere has been withdrawn above the thermal chamber.

rigid sphere. The dimensionless quantity $\hat{\eta}$ is a mathematical function of the two dimensionless variables $\tau$ and $\alpha$. An accurate determination of viscosity requires measurements of all the physical quantities entering into these equations. The calculation of $\hat{\eta}(\tau, \alpha)$ can be done to the necessary accuracy by numerical methods using a modern digital computer. Details of this calculation are given in [1], (where $\eta$ is used for our $\hat{\eta}$ ).

\subsection{The Torsion Constant of the Suspension}

The torsion wire was of an alloy of 92 percent platinum and 8 percent tungsten. This alloy was shown by Kestin, et al. [3] to be especially suitable for use as a torsion wire by reason of its low internal friction and stable elastic constant. The wire was a $51-\mathrm{cm}$ length of $0.051-\mathrm{cm}$ diam which was heat treated (to about $1300^{\circ} \mathrm{F}$ ) to relieve stresses after which the ends were hard soldered into threaded fittings.

The calibration of this viscometer requires an extremely accurate evaluation of the torsion constant $K$. It was necessary, therefore, to measure the constant at various temperatures and for various tensile loads on the wire. For this purpose, a number of cylinders of calculable moment of inertia were made. The torsion constant of this wire was measured by timing the oscillations of these cylinders. Steel and brass stock were found to be unsuitable ${ }^{2}$ for making

\footnotetext{
${ }^{2}$ Several measurements of the torsion constant were made with a cylinder machined
down in radius between each measurement. When plotted against the weights of the cylinders, the measurements for steel and brass cylinders did not fall on the same smooth curve as did measurements using aluminum or copper cylinders.
}

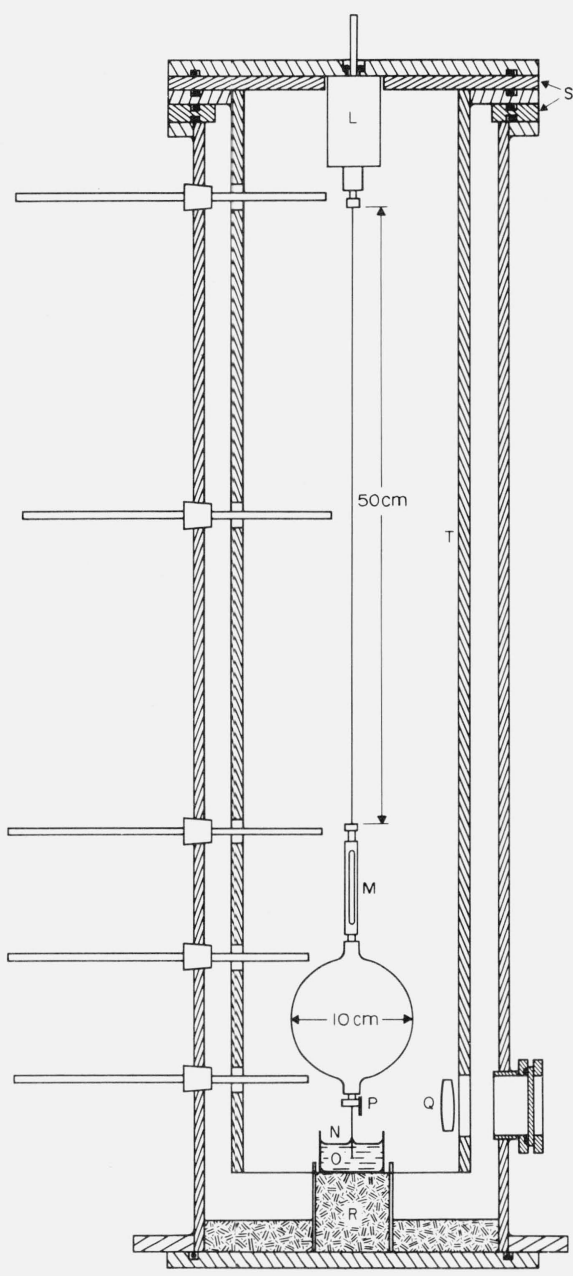

Figure 2. Cross-section of thermal chamber of viscometer with sphere in operating position.

these rods, presumably because the material was not sufficiently homogeneous. Aluminum alloy 6061 and oxygen-free high-conductivity copper were found to be suitable materials. Six cylinders were used as shown in table 1, with moments of inertia ranging from about 11,000 to $1,200 \mathrm{~g} \cdot \mathrm{cm}^{2}$ and weights ranging from 2,100 to $510 \mathrm{~g}$.

The measurements of period were made with the cylinders oscillating in torsion while suspended in the position of the sphere shown in figure 2 . The air pressure was reduced to less than $0.2 \mathrm{~mm}$ of mercury within the thermal jacket to eliminate any sig. nificant effects of the atmosphere on the period (see section 4). The temperature of the torsion wire was taken to be that indicated by the mercury in glass thermometers through the thermal jacket shown in figure 2. The temperature was controlled for a day or more before measurements were made to insure that the apparatus was in thermal equilibrium. The period measurements were made with the optical and timing systems used in the viscosity measurements. These systems are described in section (2.4). 
TABLE 1. Calibrating rods

\begin{tabular}{c|c|c|c|c|c}
\hline \hline $\begin{array}{r}\text { Rod } \\
\text { num- } \\
\text { ber }\end{array}$ & Material & $\begin{array}{c}\text { Diameter } \\
\text { at } 25{ }^{\circ} \mathrm{C}\end{array}$ & $\begin{array}{c}\text { Weight } \\
\text { in } \\
\text { vacuo }\end{array}$ & $\begin{array}{c}\text { Weight } \\
\text { before } \\
\text { drilling } \\
\text { ends, in } \\
\text { vacuo }\end{array}$ & $\begin{array}{c}\text { Moment } \\
\text { of } \\
\text { inertia }\end{array}$ \\
\hline & & inches & grams & grams & $\mathrm{g} \cdot \mathrm{cm}^{2}$ \\
1 & 6061 alloy & 1.717794 & 511.31 & 513.43 & 1221.80 \\
2 & 6061 alloy & 1.758891 & 535.58 & 537.55 & 1341.14 \\
3 & 6061 alloy & 3.010187 & 1574.36 & 1576.52 & 11520.30 \\
$3 \mathrm{a}$ & 6061 alloy & 2.655604 & 1224.80 & 1226.96 & 6978.06 \\
4 & OFHC Copper & 1.758936 & 1773.51 & 1780.19 & 4441.65 \\
5 & OFHC Copper & 1.907257 & 2093.75 & 2099.75 & 6159.75 \\
\hline
\end{tabular}

The torsion constant of the wire was found to conform to the equation

$$
K=11471.5-0.0208 g-2.6(t-25)
$$

where $K$ is the torsion constant in dyne $\mathrm{cm}, g$ is the tensile load on the wire in grams and $t$ is the temperature in degrees Celsius.

This expression for the torsion constant is accurate to better than \pm 0.015 percent through the necessary range of temperature around $25{ }^{\circ} \mathrm{C}$ and through the range of tensile load spanned by the cylinders in table 1. The dimensions of the cylinders were measured at $20{ }^{\circ} \mathrm{C}$ to \pm 20 microinches and the masses to \pm 10 milligrams. Even for measurements made with the smallest cylinder we estimate that the errors in these measurements contribute an error of at most \pm 0.004 percent of the torsion constant. We estimate a further error of \pm 0.002 percent from a possible error of, at most, 10 percent in the calculation of the temperature correction of the moment of inertia. The largest error in the calculation of the moment of inertia comes, however, from the calculation of the correction for the drilled holes, brass fittings, wax used to affix the mirror, etc. This correction amounts to $1.3 \mathrm{~g} \cdot \mathrm{cm}^{2}$. A 10-percent error in this calculation, which is a reasonable but generous estimate, would cause an error of \pm 0.010 percent in the moment of inertia of the smallest cylinder. Errors of less than $5 \mu \mathrm{s}$ in the measured period and errors of less than $0.05{ }^{\circ} \mathrm{C}$ in the temperature assigned to the wire caused a negligible error in the torsion constant.

\subsection{The Construction of the Sphere and the Determination of Its Radius}

Initially, a sphere was constructed of aluminum by machining two hemispherical cavities threaded to screw together at the equator. There was no way to be sure, however, that the fit at the threads was exact enough to prevent the flow of a significant amount of fluid into the seam between the hemispheres. Ultimately a nickel sphere was made without this seam by electroplating over a spun aluminum form. The form was machined to a sphere and ground to a tolerence of $0.001 \mathrm{in}$, then fitted with nickel polar hubs concentric to the same tolerance. It was then plated with a flash plating of copper followed by a plating of nickel to a thickness of about 0.1 in. The aluminum form was removed by washing with caustic solution flowed through holes in the polar hubs. The exterior of the sphere was then turned down so that the final sphere had a wall thickness of 0.085 in and a nominal diameter of $10 \mathrm{~cm}$. A rough calculation shows that these walls are easily stiff enough to prevent a significant change of shape under load.

The plating process was carried out at an elevated temperature $\left(45^{\circ} \mathrm{C}\right.$ to $\left.60{ }^{\circ} \mathrm{C}\right)$ so that the actual internal radius of the sphere was larger than the radius of the form at $25{ }^{\circ} \mathrm{C}$ which was $4.9535 \pm .0025 \mathrm{~cm}$. Since the difference between thermal expansion coefficients of aluminum and nickel is roughly $1 \times 10^{-5} /{ }^{\circ} \mathrm{C}$, the radius of the sphere at $25{ }^{\circ} \mathrm{C}$ should be about 4.955 $\mathrm{cm}$. The calculation of the radius in this way is not very accurate, however, and a more direct measurement is needed.

For this purpose, the mass of distilled and boiled (approximately air-free) water needed to fill the sphere at $25{ }^{\circ} \mathrm{C}$ was measured by weighing the sphere empty and full. The level of the water was adjusted to a fiducial mark in the sight glass at the top of the sphere while it was immersed in a bath of oil thermostatted at $25.00{ }^{\circ} \mathrm{C}$. A value of $0.9970478 \mathrm{~g} / \mathrm{cm}^{3}$ was used for the density of water and account was taken of air buoyancy and the volume of water in the sight glass and in the holes in the polar hubs. The measurement was repeated with two oils of low vapor pressure using values of density as measured by the Metrology Section of NBS. These measurements give a volume of the sphere at $25^{\circ} \mathrm{C}$ of $509.515 \mathrm{~cm}^{3} \pm 0.002$ percent, which is the volume of a sphere of radius $4.9548 \mathrm{~cm}$. The uncertainty of \pm 0.002 percent assigned includes the spread of a number of weighings. The uncertainty in the density of water is negligible.

A value for the equatorial radius of the sphere can be found by filling the sphere with an oil of high viscosity and measuring the period. This is approximately equivalent to measuring the moment of inertia of a rigid sphere. Oil $\mathrm{N}$ with a viscosity of about $10 \mathrm{St}$ was used for this purpose. The moment of inertia was calculated from eq (1) using the viscosity measured by a capillary instrument. This value of viscosity need not be extremely accurate since a one percent error will lead to an error in effective radius of only about 0.005 percent. ${ }^{3}$ The equatorial radius measured in this way was $4.95525 \mathrm{~cm}$. The difference between this and the radius of a sphere equal in volume to that measured is less than 0.01 percent and this difference may be taken as the uncertainty in the radius of the sphere. In fact, the evidence is that the figure of the "sphere" was close to that of a prolate spheroid with the equatorial radius slightly greater than the polar radius. Consequently, in all subsequent calculations we used a moment of inertia for the fluid calculated from the mass of the measured volume of fluid and the measured equatorial radius.

\subsection{The Moment of Inertia of the Empty Sphere}

The moment of inertia of the empty sphere was found

In fact, the independent value of the viscosity of $\mathrm{N}$ oil measured by the decrement method (see section 4 ) was within a half percent of the capillary value. 
to be $4074.45 \mathrm{~g} \cdot \mathrm{cm}^{2} \pm 0.022$ percent by timing the period of torsional oscillations at $25{ }^{\circ} \mathrm{C}$ in vacuum. This value is based on the average of a number of observations of the period of the empty sphere in a vacuum and on the previously determined value of $K$. An error of \pm 0.007 percent corresponds to the spread of a number of measurements made at different times. It is accounted for, in part, by the condensed or absorbed material on the sphere wall which apparently varied each time the sphere was subjected to a vacuum (the measured weight varied by about \pm 0.005 percent), and, further, by small changes in the mounting of the mirror. There is also a possible error of 0.015 percent associated with the value of the spring constant $K$. This error will not contribute to the scatter in the observations of period. The actual timing errors involved in measuring the period of the empty sphere were completely negligible, since they amounted to only $2 \times 10^{-4}$ percent of the period (see section 2.4).

Equation (1) applies to a sphere of fluid contained in a rigid shell of moment of inertia $I$. Thus, in calculating $I$, the effective moment of inertia of the small amounts of fluid in hub and sight glass should be added to the moment of inertia of the empty sphere. In practice, these corrections for the nickel sphere are negligible because the small cylinders of fluid are all on the axis of rotation. For the original aluminum sphere, however, the unknown amount of fluid which leaked into the equatorial seam could produce a sensible effect.

\subsection{The Period of the Oscillations}

Measurements of period were made using an electronic timer with an optical lever and photomultiplier. Light from the 0.005-in diameter straight filament of a shielded lamp shines through a window and lens $(\mathrm{Q}$ in figure 2) to a small galvanometer mirror $(\mathrm{P}$ in figure 2) fastened to a brass fitting on the lower pole of the sphere. The filament image is reflected through the lens and window to a horizontally adjustable vertical slit 0.005 in wide in an opaque film on the outside of a slotted black box enclosing a photomultiplier tube. The output from the photomultiplier tube is wired to the timer and to an oscilloscope. The photomultiplier and electronic timer arrangement was checked against the NBS standard frequency and found to measure time intervals to within $5 \mu \mathrm{s}$. Errors from this source are completely negligible, since only intervals of several seconds duration were measured. The principal difficulties of the measurement of period are to be found in the mechanical arrangements.

Actually, half periods were measured by timing the intervals between zero crossings of the light beam. At the beginning of the oscillations, there is a transient effect, referred to as a "zero-point drift" in the analysis of the apparatus [1], which dies out in a few oscillations. This effect is illustrated in figure 3 which shows some data for the aluminum alloy sphere filled with water. (The effect is especially large with low viscosity fluids and spheres of low moment of inertia.) The time interval between zero crossings is plotted against the number of the zero crossing at the beginning of the interval. The transient effect causes the even half periods to be larger than the odd ones. This effect can be used to adjust the slit, first by rough mechanical adjustment and finally by setting the trigger voltage of the timer. When the even and odd half periods approach the same limiting value, as they do in figure 3 , the slit is set to give a correct zero position.

Figure 4 shows a similar plot for the nickel sphere filled with Octoil, but for two different starting amplitudes. No effects of starting amplitude are evident although the starting effect of the previous paragraph is present. This fact is important in establishing that secondary flows due to inertial effects in the fluid are not causing a measurable effect on the period. Figure 5 shows a similar plot for $\mathrm{N}$ oil. For this liquid, with a viscosity some 50 times that of Octoil, a pronounced amplitude effect can be observed. The data after starting light amplitudes ${ }^{4}$ of 12 to 36 degrees were obtained at the same temperature and pressure within a forty minute period of time, and these data show an increase of sphere period with pass number until the amplitude has decreased to about 8 degrees. The data for a starting amplitude of the light of 8 degrees (obtained at a different ambient pressure and slightly different temperature) shows no change of period with pass number. ${ }^{5}$ In measuring the period of the sphere filled with Octoil, half periods before the 5 th pass are not used because of excessive "starting effect" and half-periods beyond the 9th pass were not used because of the very small amplitude. Thus, the average of half periods starting with the 5 th, 6th, 7th, and 8th passes (having light beam amplitudes in the range from 6 down to 3 degrees at the start of timing), were used in the calculation of viscosity.

Some measurements of period were made with the apparatus at atmospheric pressure. In such cases a correction to the observed period was ascribed to the air drag on the outer surface of the sphere. This correction was determined from data on the period of the

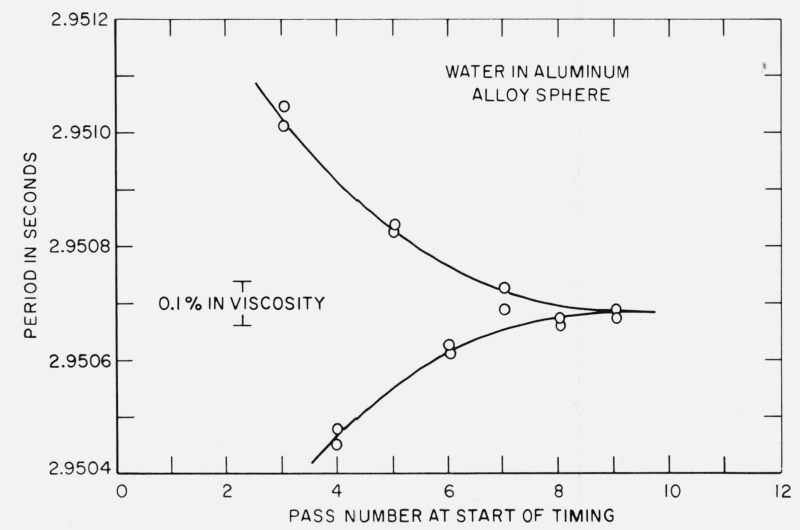

Figure 3. Period from time between zero-crossings plotted against number of zero-crossing at beginning of pass.

This example of water in the aluminum sphere illustrates the transient effect.

\footnotetext{
4 The angular amplitude of the oscillations of the light beam are twice those of the sphere ${ }^{5}$ Note that the experimental scatter for these measurements on a liquid with viscosity well outside the design range of the sphere has increased from less than 0.1 percent to about 0.5 percent.
} 


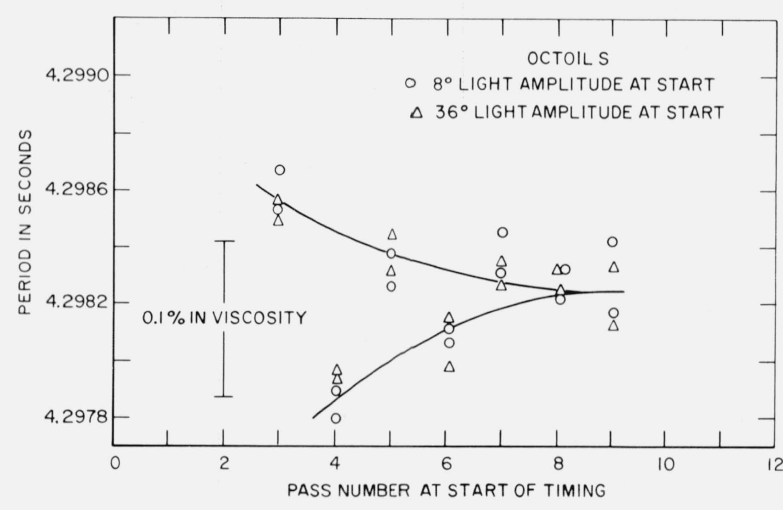

FIGURE 4. Period plotted against pass number for Octoil S showing transient effect but no amplitude effect.

sphere while empty and while filled with air-free oil $\mathrm{N}$ at pressures ranging from $0.2 \mathrm{~mm}$ of $\mathrm{Hg}$ to atmospheric. ${ }^{6}$ The data obtained with the empty sphere were interpreted as having 48 percent of the air drag correction caused by the air within the sphere, since that is the percentage of surface area exposed in the internal cavity. With these data a correction could be calculated for a given period and air pressure by linear interpolation. At $760 \mathrm{~mm}$ of $\mathrm{Hg}$ these corrections amounted to $550 \mu \mathrm{s}$. for Octoil and $470 \mu \mathrm{s}$. for $\mathrm{N}$ oil.

Vibration from nearby traffic could cause pendulum motions of the sphere and interfere with the measurement of period. A needle from the lower polar hub of the sphere (or cylinder when calibrating the torsion wire) extending into a container of high viscosity mineral oil (about $10 \mathrm{St}$ at $25^{\circ} \mathrm{C}$ ) effectively damped the swinging motion with no measurable effect on the period of the oscillation. As a further precaution. the whole apparatus was mounted on a base consisting of two 30-in concrete cubes (visible in figure 1) connected by four heavyweight steel railroad rails embedded in the concrete at each end. Vibrationinsulating pads of laminated rubber and cork composition under the corners of each concrete cube separated the base from the concrete floor.

\subsection{Miscellaneous}

Octoil $\mathrm{S}$ is a commercial di(2-ethylhexyl) sebacate that has been highly purified by molecular distillation. It was chosen because its low vapor pressure (about $6 \times 10^{-7} \mathrm{~mm} \mathrm{Hg}$ at $25^{\circ} \mathrm{C}$ ) made it suitable for use under vacuum conditions down to about $10^{-3} \mathrm{~mm} \mathrm{Hg}$, and its viscosity (about $19 \mathrm{cSt}$ at $25^{\circ} \mathrm{C}$ ) is within the 10 to $150 \mathrm{cSt}$ design range of the spheres.

Oil $\mathrm{N}$ is a Pennsylvania bright stock similar in viscosity to the discontinued SAE 70 motor oil. It was chosen because its low volatility under vacuum and its viscosity (about $1000 \mathrm{cSt}$ ) made it suitable for determining the effective inner radius of the sphere. (See section 2.2) The viscosity is low enough to permit filling and emptying of the sphere with reasonable ease and is high enough so that the period of oscilla-

${ }^{6}$ Account must be taker. of the change of viscosity with pressure (see section 3 ). tion of the filled sphere depends only slightly on viscosity.

Pressures below $1 \mathrm{~mm}$ of mercury were measured by a McLeod gage. Pressures between $1 \mathrm{~mm}$ and 1 atm were determined by suitable manometers, one of which is shown in figure 1. Atmospheric pressure was measured by a conventional mercury barometer. A mechanical vacuum pump was used to obtain the pressures less than atmospheric.

Mercury-in-glass thermometers ( $\mathrm{K}$ in figure 2), graduated in tenths of degrees Celsius and calibrated in hundredths of degrees, were used for measuring the temperature inside the housing at appropriate positions. The calibration took into account the horizontal position of the thermometers and corrected for the ambient pressure at the bulb.

Whenever the sphere was filled, it was immersed in a constant temperature oil bath at $25.00 \pm .01{ }^{\circ} \mathrm{C}$ while the oil level in the sphere sight glass was adjusted to a fiducial line. A syringe with a long needle was used for adding or removing oil. The bath temperature was controlled by a large-bulb mercury-in-glass thermoregulator with fixed enclosed platinum points. The sphere and sight glass could be used as a dilatometer to calculate changes in density associated with temperature and pressure variations.

When the wire constant was being determined, when the moment of inertia of the empty sphere was being measured, or when the sphere was being used for viscosity determinations, oil was pumped from the constant temperature oil bath through the copper coil surrounding the sphere housing. The thermoregulator in the oil bath was set at $24.7{ }^{\circ} \mathrm{C}$ to allow for a $0.3{ }^{\circ} \mathrm{C}$ temperature rise in the oil line following the pump, while a similar thermoregulator set at $24.9{ }^{\circ} \mathrm{C}$ and enclosed in a perforated heavy-wall copper tube located at the base of the housing, near the copper coil, controlled the room air conditioner. This arrangement maintained the ambient temperature of the housing at $25.0^{\circ} \mathrm{C}$.

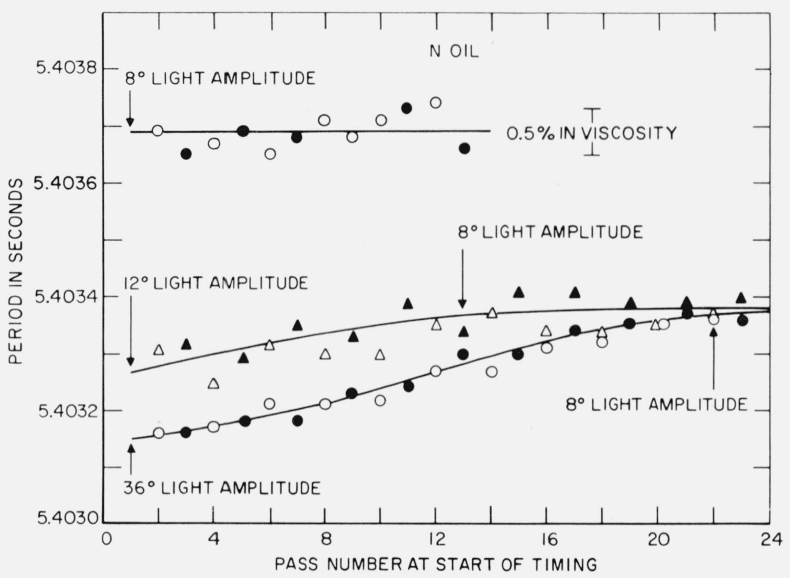

Figure 5. Period plotted against pass number for $N$ oil showing amplitude effect.

The data at $8^{\circ}$ light amplitude was taken at temperature different than for the other data. 


\section{Calculation of Viscosity from Measured Period}

The equation giving kinematic viscosity (= viscosity/ density), in terms of the measured period, $T$, and parameters of the sphere is repeated here, with $b$, the equatorial radius, replacing $R$, the radius of a perfect sphere of the same volume (see section 2.2)

$$
\begin{aligned}
& \nu=b^{2} \sqrt{\frac{K}{I_{0}}} \hat{\vartheta}(\alpha, \tau) \\
& \alpha=\frac{I}{I_{0}}, I_{0}=\frac{2}{5} \rho V b^{2} \\
& \tau=\frac{T}{2 \pi} \sqrt{\frac{K}{I_{o}}}
\end{aligned}
$$

$b=$ equatorial radius $=4.95525 \mathrm{~cm} \delta b / b= \pm 1.0$ $\times 10^{-4}$ (sec. 2.2$)$

$K=$ torsion constant of wire $=11455.54$ dyn-cm $\delta K / K= \pm 1.5 \times 10^{-4}$ (sec. 2.1 )

$I=$ measured moment of inertia of empty sphere $=4074.445 \mathrm{~g} \cdot \mathrm{cm}^{2} \delta I / I=\delta K / K$

$I_{0}=$ moment of inertia of liquid in sphere moving as rigid body

$V=$ volume of sphere excluding sight glass and hubs $=509.515 \mathrm{~cm}^{3}$

$\rho=$ density of test fluid

$\delta I_{0} / I_{0}=\delta \rho / \rho+\delta V / V+2 \delta b / b$

$\delta V / V= \pm 2 \times 10^{-5}$

$\delta \rho / \rho= \pm 2 \times 10^{-5}$

The above uncertainties refer to systematic ${ }^{7}$ errors only, that is those associated with constants of the apparatus and the density of the test fluid. The systematic error in period was less than five microseconds and the periods were two seconds or longer. That in weighings was less than $1 \mathrm{mg}$ in values of 270 grams or greater. Neither contribute significantly to the total systematic error, though there were differences between replicate determinations due to variations in the mass of the sphere (see section 2.3).

The functional relationships between $\hat{\eta}, \alpha$, and $\tau$ comes from the solution of the equations of motion assuming that the fluid motion has no component in planes containing the axis of rotation of the sphere (no secondary flow). It is an implicit relation which can be used to calculate the $\tau$ 's corresponding to given values of $\hat{\eta}$ and $\alpha$. A set of such solutions was computed and tabulated with a fine enough grid so that linear interpolation was permissible. Thus, using an observed period $T$ (from which $\tau$ could be calculated) and a known $\alpha$, a corresponding value of $\hat{\eta}$ could be found from the computed tables by interpolation and a corresponding value of $\nu$ obtained.

Example of calculation of viscosity from period:

\footnotetext{
${ }^{7}$ These errors will not produce a scatter among replicate determinations of the viscosity of a given fluid.
}

Air-free Octoil S at $0.24 \mathrm{~mm} \mathrm{Hg}, 24.97^{\circ} \mathrm{C} . \rho=0.91014$ $\mathrm{g} / \mathrm{cm}^{3}$

Observed period, $T=4.297637 \mathrm{~s}$.

The parameters of the sphere listed above are then:

$$
\begin{aligned}
I_{0} & =\frac{2}{5} V \rho b^{2}=4554.660 \mathrm{~g} \cdot \mathrm{cm}^{2} \\
\tau & =\frac{1}{2 \pi} \sqrt{\frac{K}{I_{0}}}=1.084750 \\
\alpha & =I / I_{0}=0.894566
\end{aligned}
$$

In the table of calculated values of $\tau$ is a line with $\alpha=0.89450, \tau=1.084737, \hat{\eta}=0.0050100$, and in this region of the table $\Delta \hat{\eta} / \Delta \tau=0.07042, \Delta \hat{\eta} / \Delta \alpha=-0.03380$. ihus, a linear interpolation gives us for the $\hat{\eta}$ corresponding to the observed $\tau$ and $\alpha$ :

$$
\hat{\eta}=0.0050086
$$

from which we calculate

$$
\nu=\hat{\eta} b^{2}\left(K / I_{0}\right)^{1 / 2}=19.504 \text { cst. }
$$

The systematic error associated with this value may be calculated in terms of the independent constants of the experiment $b, K, \rho$, and $V$ as

$$
\begin{aligned}
\frac{\delta \nu}{\nu} & =\left(1-\frac{\tau}{\hat{\eta}} \frac{\partial \hat{\eta}}{\partial \tau}-2 \frac{\alpha}{\hat{\eta}} \frac{\partial \hat{\eta}}{\partial \alpha}\right)\left(\frac{\delta b}{b}+\frac{\delta \rho}{\rho}\right) \\
& +\frac{1}{2}\left(1+\frac{\tau}{\hat{\eta}} \frac{\partial \hat{\eta}}{\partial \tau}+2 \frac{\alpha}{\hat{\eta}} \frac{\partial \hat{\eta}}{\partial \alpha}\right)\left(\frac{\delta K}{K}+\frac{\delta V}{V}\right) \\
& = \pm 6.2 \times 10^{-4},
\end{aligned}
$$

this 0.06 percent is the sum of the absolute values of the four independent contributions, that associated with $K$ giving 0.03 percent, that with $b$ giving 0.02 percent, while the other two contributions are each less than 0.01 percent.

In order to compare this value of viscosity to that obtained at atmospheric pressure with a capillary instrument, one must know the effect of pressure on the viscosity. At $25.00{ }^{\circ} \mathrm{C}$ and pressures below 10 $\mathrm{mm}$ of $\mathrm{Hg}$, the viscosities of Octoil $\mathrm{S}$ and $\mathrm{N}$ oil are lower than that at atmospheric pressure by 0.20 percent and 0.30 percent respectively. This value can be calculated for Octoil from published measurements of viscosity and density as a function of pressure for both Octoil and Plexol, a less refined commercial grade of the same chemical. These liquids are labeled samples $1-\mathrm{A}$ and 19-D respectively in an ASTM report on pressure effects on lubricating fluids [4]. The effect of pressure on the viscosity of $\mathrm{N}$ oil was measured with relative viscometers in our laboratory, and the effect on the density of both oils measured using the sphere as a dilatometer.

Corrections of $\rho$ and $\nu$ for the effect of being air-free were also needed for both oil $\mathrm{N}$ and Octoil S. For airfree oil $\mathrm{N}$ at $25.00{ }^{\circ} \mathrm{C}$ the density was greater by 
$0.00007 \mathrm{~g} / \mathrm{cm}^{3}$ and the viscosity was greater by 0.038 St $(0.36$ percent $)$ than that of air saturated oil $\mathrm{N}$; for Octoil $\mathrm{S}$ the corresponding density difference is $0.000010 \mathrm{~g} / \mathrm{cm}^{3}$ and the viscosity difference is 0.00068 St $(0.35$ percent). With oil $\mathrm{N}$, these corrections were estimated from relative measurements with a capillary viscometer and from weighings of a known volume in the NBS density laboratory. Air-free Octoil S (much lower in viscosity than oil $\mathrm{N}$ ) apparently dissolved air rapidly while being transferred from the sphere to capillary viscometers or volumetric flasks. Accordingly, for Octoil $\mathrm{S}$ these corrections were estimated from relative measurements made with the sample in the sphere and at atmospheric pressure.

\section{Determination of the Viscosity of $\mathbf{N}$ oil by Measurement of Decrement}

Since the viscosity of oil N is used in the determination of the radius of the sphere (see section 2.2) the apparatus was adapted to give an independent value of this viscosity through measurement of the decrement of the torsional oscillation.

The apparatus was designed for the determination of viscosities by measurement of periods, and originally, no provision was made for determining decrement. We found, however, that quite accurate decrements could be measured through timing successive passes of the light beam through a small interval near the zero rest position. The single 0.005 -in slit in front of the photomultiplier tube was replaced with two similar slits with their centers 0.065 inches apart. At rest, the light beam triggering edge was adjusted midway between the two slits. In motion, the light beam triggering edge started the timer as it passed the center of one slit and stopped it as it passed the corresponding position in the second slit. The 0.065 -in interval was chosen to be large enough for good accuracy of timing and small enough so that the average velocity over the interval would be nearly the same as the instantaneous velocity at the zero rest position.

For computing the viscosity from decrement, the ratios of timings for the 0.065 -in light beam travel near the zero rest position, for successive passes in the same direction, were used. The ratio was measured for beam travel in each direction and then averaged to minimize the error caused by any inexactitude in centering of the interval. If $t_{n}$ denotes the time for nth traverse of the interval, $D$ denotes a decrement defined by

$$
D=\left(\log _{e} t_{n} / t_{n+1}\right) / \pi \text {. }
$$

This decrement must be corrected for the damping caused by the internal friction of the torsion wire and the viscous "air-drag."

Decrement measurements were made with the empty sphere oscillating in air from atmospheric pressure down to $0.008 \mathrm{~mm} \mathrm{Hg}$. The damping decreased with decreasing pressure at pressures above $1.0 \mathrm{~mm}$ $\mathrm{Hg}$, remained almost constant while the pressure was between 1.0 and $0.1 \mathrm{~mm}$, and again decreased as the pressure was decreased below $0.1 \mathrm{~mm}$. Measurements of the period of the empty sphere showed no change throughout the range of pressures from 1.0 to 0.01 $\mathrm{mm} \mathrm{Hg}$. Presumably, the effects of pressure changes down to pressures of $1.0 \mathrm{~mm}$ of $\mathrm{Hg}$ are primarily through changes of the density of air while those for pressures below $0.1 \mathrm{~mm}$ of $\mathrm{Hg}$ are associated with the changing viscosity or mean free path of the air. Data were obtained with oil $\mathrm{N}_{35}$ and Octoil $\mathrm{S}$ at pressures down to about $0.1 \mathrm{~mm} \mathrm{Hg}$.

In the range of 0.1 to $1 \mathrm{~mm} \mathrm{Hg}$ ambient pressure, the magnitude of the corrections to the decrement, $D$, were estimated as:

correction due to internal friction of wire 0.000067 correction due to air drag on sphere 0.000031 .

These should be compared to a total decrement for oil $\mathrm{N}$ of about 0.04 .

The viscosity of oil $\mathrm{N}$ obtained by this decrement method was within 0.5 percent of the value obtained by capillary methods relative to the currently accepted value for the viscosity of water at $20^{\circ} \mathrm{C}$.

\section{Results}

The collection of measured values of kinematic viscosity of Octoil $S$ is shown in table 2 . These meassurements were made at various times over a period of about two years. Values measured with the original machined aluminum sphere are included and are marked with one or two asterisks to indicate two conditions of smoothness of the interior surface. ${ }^{8}$ Since the temperature and pressure varied slightly for the different measurements, we compare them in terms of the difference between the viscosity measured in the sphere and that measured in a relative capillary viscometer, calibrated in terms of the generally accepted value for the viscosity of water, at the same temperature and pressure [2]. Measurements were also made on several test fluids outside the design range of the apparatus to see if the deviations are consistent with our analysis of the instrument. These fluids, water and two of the standard viscosity fluids formerly distributed by NBS, each had a vapor pressure at room temperature which excluded the possibility of operating the instrument in vacuum. Consequently, all the determinations of viscosity on these three fluids involved a period corrected to account for air drag (see section 2.4.). The results are shown in table 3 . Determinations of viscosity by the decrement method are found in table 4.

A systematic error of \pm 0.06 percent was estimated for the measurement of the viscosity of Octoil $\mathrm{S}$ as noted in section 3. Calculations for water, Oil D, and Oil $\mathrm{L}$ yielded values ranging from \pm 0.05 to \pm 0.07 percent, an insignificant variation, with an average for the four calculated values of \pm 0.065 percent. We may therefore assign an estimated systematic error of \pm 0.07 percent to the measurement of any fluid in this range of viscosity (1 to $90 \mathrm{cSt}$ ).

\footnotetext{
${ }^{8}$ The aluminum sphere consisted of two hemispheres which screwed together at the equator. The resulting seam between the hemispheres introduced an error in the measured viscosity which was probably as much as 0.1 percent.
} 
TABLE 2. Comparison of viscosity of Octoil $S$ (in centistokes) measured by sphere period (absolute method) and capillary (relative method with value calculated based on viscosity of water at $20{ }^{\circ} \mathrm{C}=1.004 \mathrm{cSt}$ )

\begin{tabular}{|c|c|c|c|}
\hline Fluid and condition & $\begin{array}{l}\text { Ambient } \\
\text { pressure }\end{array}$ & $\begin{array}{c}\nu_{\text {sphere. }} \\
\text { from period } \\
\text { measurements }\end{array}$ & $\frac{\nu_{\text {sphere }}-\nu_{\text {cap }}}{\nu_{\text {cap }}} \times 100$ \\
\hline \multirow{6}{*}{$\begin{array}{l}\text { Octoil S, air-saturated } \\
\left(\nu_{\text {cap }}=19.397\right)\end{array}$} & $m m H g$ & $c S t$ & percent \\
\hline & 758 & 19.475 & 0.404 \\
\hline & 757 & 19.477 & .414 \\
\hline & 745 & 19.468 & .366 \\
\hline & 738 & 19.468 & .364 \\
\hline & & 19.470 & .375 \\
\hline Average & atmos & 19.472 & 0.385 \\
\hline \multirow{8}{*}{$\begin{array}{l}\text { Octoil S, air-free } \\
\left(\nu_{\text {cap }}=19.465\right)\end{array}$} & 766 & 19.541 & 0.389 \\
\hline & 766 & 19.539 & .382 \\
\hline & 766 & 19.537 & .369 \\
\hline & $\begin{array}{l}750 \\
759\end{array}$ & $\begin{array}{l}19.544 \\
19.548\end{array}$ & $\begin{array}{l}.404 \\
.427\end{array}$ \\
\hline & 759 & 19.547 & .419 \\
\hline & 760 & 19.550 & .435 \\
\hline & 740 & 19.541 & .390 \\
\hline & 755 & 19.540 & .383 \\
\hline Average & atmos & 19.543 & 0.400 \\
\hline \multirow{3}{*}{$\begin{array}{l}\text { Octoil S, air-free } \\
\left(\nu_{\text {cap }}=19.426\right)\end{array}$} & 0.24 & 19.484 & 0.297 \\
\hline & .16 & 19.497 & .368 \\
\hline & $\begin{array}{l}2.0 \\
0.9\end{array}$ & $\begin{array}{l}19.497 \\
19.510\end{array}$ & $\begin{array}{l}.363 \\
.433\end{array}$ \\
\hline Average & уac & 19497 & 0365 \\
\hline & & & \\
\hline Octoil S, average, all & & & 0.388 \\
\hline \multirow{5}{*}{$\begin{array}{l}\text { Octoil } S,{ }^{*} \text { air-free } \\
\left(\nu_{\text {cap }}=19.465\right)\end{array}$} & 756 & 19.533 & 0.347 \\
\hline & 756 & 19.517 & .269 \\
\hline & $\begin{array}{l}756 \\
755\end{array}$ & 19.513 & .245 \\
\hline & $\begin{array}{l}753 \\
753\end{array}$ & $\begin{array}{l}19.508 \\
19.524\end{array}$ & $\begin{array}{l}.221 \\
.303\end{array}$ \\
\hline & 753 & 19.525 & .307 \\
\hline Average & atmos & 19.520 & 0.282 \\
\hline \multirow{4}{*}{$\begin{array}{l}\text { Octoil } \mathrm{S},{ }^{*} \text { air-free } \\
\left(\nu_{\text {cap }}=19.426\right)\end{array}$} & 0.15 & 19.495 & 0.356 \\
\hline & .15 & 19.488 & .321 \\
\hline & .13 & 19.483 & $\begin{array}{r}.293 \\
349\end{array}$ \\
\hline & .12 & $\begin{array}{l}19.492 \\
19.495\end{array}$ & $\begin{array}{l}.342 \\
.354\end{array}$ \\
\hline Average & vac & 19.491 & 0.333 \\
\hline Octoil $\mathrm{S},{ }^{*}$ average, all & & & 0.305 \\
\hline \multirow[t]{2}{*}{ Octoil S, ${ }^{* *}$ air-free } & 756 & 19.570 & 0.538 \\
\hline & 756 & 19.572 & .549 \\
\hline$\left(\nu_{\text {cap }}=19.465\right)$ & 760 & 19.556 & .465 \\
\hline Average & atmos & 19.566 & 0.517 \\
\hline Octoil $S,{ }^{* *}$ air-free & 1.0 & 19.522 & 0.493 \\
\hline \multirow{2}{*}{$\left(\nu_{\text {cap }}=19.426\right)$} & 0.22 & 19.524 & .504 \\
\hline & 0.22 & 19.528 & .524 \\
\hline Average & vac & 19.525 & 0.507 \\
\hline Octoil $\mathrm{S},{ }^{* *}$ average, all & & & 0.512 \\
\hline
\end{tabular}

* In aluminum alloy sphere as machined.

** In aluminum alloy sphere after polishing interior. 
TABLE 3. Comparison of viscosities (in centistokes) measured by sphere period (absolute method) and capillary (relative method with value calculated based on viscosity of water at $20{ }^{\circ} \mathrm{C}=1.004 \mathrm{cSt}$ ).

\begin{tabular}{|c|c|c|c|}
\hline Fluid and condition & $\begin{array}{l}\text { Ambient } \\
\text { pressure }\end{array}$ & $\begin{array}{c}\nu_{\text {sphere. }} \\
\text { from period } \\
\text { measurements }\end{array}$ & $\frac{\nu_{\text {sphere }}-\nu_{\text {cap }}}{\nu_{\text {cap }}} \times 100$ \\
\hline & $m m \mathrm{Hg}$ & $c S t$ & percent \\
\hline $\begin{array}{l}\mathrm{L}_{31}, \text { air-saturated } \\
\left(\nu_{c a p}=86.752\right)\end{array}$ & $\begin{array}{l}752 \\
752 \\
752 \\
755 \\
758 \\
758\end{array}$ & $\begin{array}{l}86.991 \\
87.020 \\
86.996 \\
87.047 \\
86.965 \\
86.983\end{array}$ & $\begin{array}{r}0.275 \\
.309 \\
.281 \\
.340 \\
.246 \\
.266\end{array}$ \\
\hline Average & atmos & 87.000 & 0.286 \\
\hline $\begin{array}{l}\text { Water, air-saturated } \\
\left(\nu_{c a p}=0.89294\right)\end{array}$ & $\begin{array}{l}745 \\
746 \\
752 \\
754 \\
759 \\
759 \\
753 \\
756 \\
756 \\
754\end{array}$ & $\begin{array}{r}0.90020 \\
.89992 \\
.89928 \\
.89857 \\
.89855 \\
.89828 \\
.90087 \\
.90199 \\
.90196 \\
.90191\end{array}$ & $\begin{array}{r}0.813 \\
.782 \\
.710 \\
.631 \\
.628 \\
.598 \\
.888 \\
1.013 \\
1.010 \\
1.005\end{array}$ \\
\hline Average & atmos & 0.90015 & 0.808 \\
\hline $\begin{array}{l}\text { Water, air-free } \\
\left(\nu_{\text {cap }}=0.89294\right.\end{array}$ & $\begin{array}{l}760 \\
760 \\
759 \\
754 \\
754 \\
752 \\
751 \\
751 \\
752 \\
751 \\
751 \\
757 \\
759 \\
758 \\
759 \\
761 \\
755 \\
755 \\
759\end{array}$ & $\begin{array}{r}0.89518 \\
.89544 \\
.89518 \\
.90050 \\
.90041 \\
.90147 \\
.90215 \\
.90168 \\
.89693 \\
.89681 \\
.89654 \\
.89699 \\
.90098 \\
.90139 \\
.90128 \\
.89989 \\
.89632 \\
.89723 \\
.89663\end{array}$ & $\begin{array}{r}0.251 \\
.280 \\
.251 \\
.847 \\
.837 \\
.955 \\
1.031 \\
.978 \\
.447 \\
.433 \\
.403 \\
.454 \\
.900 \\
.946 \\
.934 \\
.778 \\
.378 \\
.480 \\
.413\end{array}$ \\
\hline Average & atmos & 0.89858 & 0.631 \\
\hline $\begin{array}{l}\mathrm{D}_{14}, \text { air-saturated } \\
\left(\nu_{\text {cap }}=3.1697\right)\end{array}$ & $\begin{array}{l}752 \\
751 \\
751 \\
742\end{array}$ & $\begin{array}{l}3.1859 \\
3.1856 \\
3.1855 \\
3.1856\end{array}$ & $\begin{array}{r}0.512 \\
.502 \\
.498 \\
.502\end{array}$ \\
\hline Average & atmos & 3.1857 & 0.504 \\
\hline $\begin{array}{l}\mathrm{D}_{14}, \text { air-saturated } \\
\left(\nu_{\text {cap }}=3.1751\right)\end{array}$ & $\begin{array}{l}756 \\
755 \\
754 \\
752 \\
756 \\
748\end{array}$ & $\begin{array}{l}3.1913 \\
3.1885 \\
3.1934 \\
3.1932 \\
3.1937 \\
3.1936\end{array}$ & $\begin{array}{l}0.511 \\
.422 \\
.577 \\
.569 \\
.585 \\
.584\end{array}$ \\
\hline Average & atmos & 3.1923 & 0.541 \\
\hline $\mathrm{D}_{14}$, average, all & & & 0.526 \\
\hline
\end{tabular}


TABLE 4. Comparison of viscosities (in centistokes) measured by decrement method and capillary (relative method with value calculated based on viscosity of water at $20^{\circ} \mathrm{C}=1.004 \mathrm{cSt}$ ).

\begin{tabular}{|c|c|c|c|}
\hline Fluid and condition & $\begin{array}{l}\text { Ambient } \\
\text { pressure }\end{array}$ & $\begin{array}{c}\nu_{\text {sphere }} \text { from } \\
\text { decrement } \\
\text { measurements }\end{array}$ & $\frac{\nu_{\text {sphere }}-\nu_{\text {cap }}}{\nu_{\text {cap }}} \times 100$ \\
\hline \multirow{5}{*}{$\begin{array}{c}\mathrm{N}_{35}, \text { air-free } \\
\left(\nu_{\text {cap }}=1048.0\right) \\
\text { Average }\end{array}$} & $m m \mathrm{Hg}$ & $c S t$ & percent \\
\hline & 762 & 1054.3 & 0.603 \\
\hline & 761 & 1052.8 & .457 \\
\hline & 753 & 1053.8 & .555 \\
\hline & atmos & 1053.6 & 0.538 \\
\hline \multirow[t]{6}{*}{$\mathrm{N}_{35}$, air-free } & 632 & 1052.3 & 0.460 \\
\hline & 524 & 1050.7 & .354 \\
\hline & 303 & 1050.0 & .374 \\
\hline & $\begin{array}{l}164 \\
145\end{array}$ & $\begin{array}{l}1051.2 \\
1051.8\end{array}$ & $\begin{array}{l}.540 \\
.606\end{array}$ \\
\hline & 59 & 1050.4 & .510 \\
\hline & 21 & 1050.2 & .497 \\
\hline Average & & & 0.477 \\
\hline \multirow{4}{*}{$\begin{array}{l}\mathrm{N}_{35}, \text { air-free } \\
\left(\nu_{c a p}=1044.9\right)\end{array}$} & 2.5 & 1050.4 & 0.528 \\
\hline & 2.0 & 1050.1 & .500 \\
\hline & $\begin{array}{r}0.45 \\
25\end{array}$ & 1050.5 & $\begin{array}{r}.540 \\
623\end{array}$ \\
\hline & & & \\
\hline Average & vac & 1050.6 & 0.548 \\
\hline $\mathrm{N}_{35}$, average, all & & & 0.510 \\
\hline \multirow{6}{*}{$\begin{array}{l}\text { Octoil S, air-free } \\
\left(\nu_{\text {cap }}=19.465\right)^{\prime}\end{array}$} & 762 & 19.391 & -0.382 \\
\hline & $\begin{array}{l}762 \\
760\end{array}$ & $\begin{array}{l}19.395 \\
19.301\end{array}$ & -.360 \\
\hline & $\begin{array}{l}760 \\
760\end{array}$ & $\begin{array}{l}19.391 \\
19.452\end{array}$ & $\begin{array}{l}-.382 \\
-.067\end{array}$ \\
\hline & 760 & 19.432 & -.167 \\
\hline & 758 & 19.479 & .070 \\
\hline & 754 & 19.483 & .093 \\
\hline Average & atmos & 19.432 & -0.171 \\
\hline \multirow[t]{7}{*}{ Octoil S, air-free } & 645 & 19.460 & 0.004 \\
\hline & 531 & 19.450 & -.016 \\
\hline & 431 & 19.469 & .107 \\
\hline & $\begin{array}{l}363 \\
317\end{array}$ & $\begin{array}{l}19.516 \\
19.463\end{array}$ & $\begin{array}{l}.365 \\
107\end{array}$ \\
\hline & $\begin{array}{l}318 \\
154\end{array}$ & $\begin{array}{l}19.463 \\
19.453\end{array}$ & $\begin{array}{l}.106 \\
.100\end{array}$ \\
\hline & 150 & 19.486 & .265 \\
\hline & 37 & 19.467 & .200 \\
\hline Average & & & 0.142 \\
\hline \multirow{6}{*}{$\begin{array}{l}\text { Octoil S, air-free } \\
\left(\nu_{\text {cap }}=19.426\right)\end{array}$} & 9 & 19.468 & 0.216 \\
\hline & 9 & 19.446 & .102 \\
\hline & 8 & 19.427 & .005 \\
\hline & $\begin{array}{l}3 \\
2\end{array}$ & $\begin{array}{l}19.422 \\
19.493\end{array}$ & $\begin{array}{r}-.019 \\
-.344\end{array}$ \\
\hline & 0.33 & 19.441 & .075 \\
\hline & .29 & 19.423 & -.014 \\
\hline Average & vac & 19.446 & 0.101 \\
\hline Octoil $\mathrm{S}$, average, all & & & 0.029 \\
\hline
\end{tabular}

In addition there was observed, of course, a variability between replicate measurements of the same fluid. There are primarily two factors which are responsible for this. First we expect small variations in the actual temperature of the fluid and the torsion wire which we estimate to be $\pm 0.005{ }^{\circ} \mathrm{C}$ and \pm 0.05
${ }^{\circ} \mathrm{C}$ respectively. This will affect the viscosity of the fluid being measured and the torsion constant of the wire. The effect on dimensions of the sphere is not significant. The second factor, and the major one, is the observed variation in the weight of the sphere which seems to account for the variability of 0.007 
percent in the moment of inertia of the empty sphere when measured in vacuum. For measurements at atmospheric pressure this variability in the measured moment of inertia increased to 0.01 percent. Presumably these variations in $I$ will also occur between measurements of viscosity and we have calculated the variability in the measured viscosity by making this assumption.

Measurements of viscosity by the period method are plotted in figure 6 . The results are presented in terms of the percent deviation of individual measurements from the results of relative viscometry with capillary instruments taking the viscosity of water as 1.002 centipoise ( 1.004 centistokes) at $20^{\circ} \mathrm{C}$.

The dashed lines are centered on the mean of the observed points for each liquid to indicate the estimate of spread of errors calculated above. The agreement between the observed variability and that estimated is as close as we could expect. For water, Octoil S, and Oil $L$ the agreement is almost exact. For Oil D the observed spread is smaller than that estimated, probably because of the limited number of observations. The calculated systematic error and variability for period measurements on Oil N were 3.9 percent and 1.1 percent respectively. The spread of a few observations of the period with Oil $\mathrm{N}$ in the sphere were consistent with the latter value; the dashed lines are continued toward this range of viscosity merely to indicate that we expected, and observed, greater variability on both sides of the design range.

In an attempt to see if the smoothness of the inner surface of the sphere might have any influence on the observed period, the original tool marks in the aluminum sphere were polished off, changing the roughness ${ }^{9}$ from the original 20 microinches to 5 microinches. Of course, a new set of constants for the sphere had to be determined after this polishing. Table 2 includes values of viscosity obtained with the aluminum sphere both before $(*)$ and after $(* *)$ this polishing procedure. The difference of about 0.2 percent is consistent with a reasonable set of error estimates for the aluminum sphere, in which we know that there is an uncertainty in the determination of $I$ due to the seam between the two hemispheres (see section 2.3). If the roughness of our spheres did influence our measurements, we would

${ }^{9}$ These values represent the arithmetical average of the irregularities in surface height as measured with a profilometer.

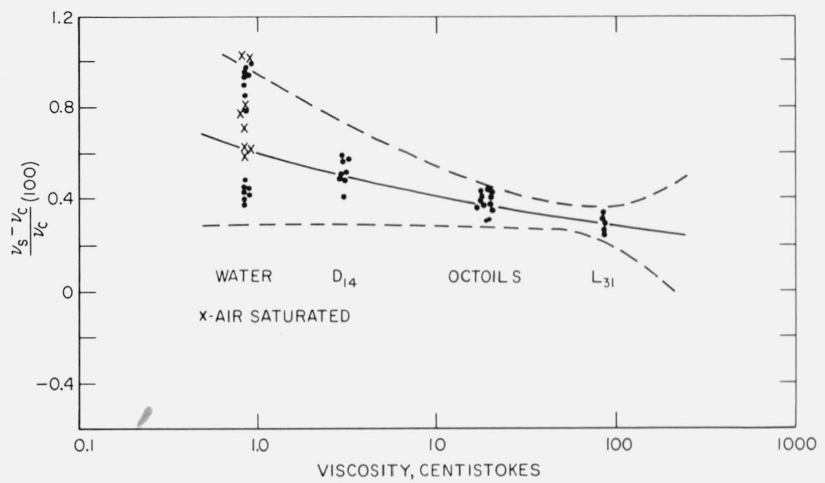

Figure 6. The difference in percent between the measurement of viscosity with the sphere and the relative value by capillary measurement.

The zero corresponds to capillary measurements based on the current standard of $1.002 \mathrm{cP}$ for the viscosity of water at $20^{\circ} \mathrm{C}$.

expect greater roughness to correspond to higher values of viscosity. The difference observed here was in the opposite direction. It is clear from figure 6 that all the measurements of viscosity made by timing the period of the sphere are mutually consistent among themselves. It is also clear from figure 6 that our measurements of the viscosity in the design range of the apparatus (Octoil S and Oil L) are 0.3 percent or 0.4 percent higher than the relative measurements with a capillary instrument taking the viscosity of water as $1.002 \mathrm{cP}(1.004 \mathrm{cSt})$ at $20{ }^{\circ} \mathrm{C}$. These errors are beyond our estimate of the maximum possible error. We can only conclude that there is an unidentified systematic error in one or both of these methods of measuring viscosity.

\section{References}

[1] Kearsley, E. A., An analysis of an absolute torsional pendulum viscometer, Trans. Soc. Rheol. III, 69-80 (1959).

[2] Marvin, R. S., The accuracy of measurements of viscosity of liquids, J. Res. Nat. Bur. Stand. (U.S.). 75A (Physics and Chem.), No. 6, 535-540 (Nov.-Dec. 1971).

[3] Kestin, J., and Moszynski, J. M., An experimental investigation of the internal friction of thin platinum alloy wires at low frequencies, Brown University Report, AF 891/11, July 1958.

[4] ASME Pressure Viscosity Report, II, Viscosity and density of over 40 lubricating fluids of known composition at pressures to $150,000 \mathrm{Psi}$ and temperatures to $425^{\circ} \mathrm{F}$ (1953).

(Paper 75A6-685) 